Kalpa Publications in Civil Engineering
Volume 1, 2017, Pages 37-44
$\begin{gathered}\text { ICRISET2017. International Conference on Re- } \\ \text { search and Innovations in Science, Engineering } \\ \text { \&Technology. Selected papers in Civil Engineering }\end{gathered}$

\title{
A Study on the Developing Concepts of Underwater Construction
}

\author{
Zaran D. Patel ${ }^{1}$, Dr. Jayeshkumar Pitroda ${ }^{2}$ \\ ${ }^{1}$ Second year B. Tech. Student, Civil engineering, B.V.M. Engineering college, Vallabh Vidyanagar, \\ Gujarat, India \\ zaranpate184@gmail.com \\ ${ }^{2}$ Assistant Professor, Civil Engineering Department, B.V.M. Engineering college, Vallabh \\ Vidyanagar, Gujarat, India \\ jayesh.pitroda@bvmengineering.ac.in
}

\begin{abstract}
Population in India is increasing rapidly and reached approximately 127 crores with average growth of $1.6 \%$ every year. Traffic Congestion is one of the major problems that India is facing and it has a massive impact on the quality of air, time of travelling, trade and cost. It has been noted that the government are trying their best in order to come up to this problem by creating structures such as Tunnels, Subways, Flyovers and Bridges. But unfortunately it fails as does not match up with the increase of population and due to less amount of land available for the construction. In this report there is a study on the construction of the buildings and structures with a new technology of constructing under the water. It has been noted that the underwater buildings exist since year 1960 but no one was aware of it. The underwater construction of the buildings can be advantageous to the people and the environment if proper techniques are used and if people get success in achieving such structures. If such technology is adapted everything can be built underwater such as buildings, houses, shopping complex, museums, entertainment hub, restaurants, hotels, sports stadiums etc. This can lead to a progressive and a luxurious life to the people and they can even enjoy their holidays at such places. Encouragement of underwater building is provided by the glamorous view beneath the water of fishes, sea beds, different creatures and coral reefs. This paper discuss about the materials which should be used for the construction of underwater buildings, ways of building and special requirements, the possibility of such constructions, advantages and disadvantages of underwater buildings, the impact of such buildings on environment, effect on the social life and transportation.
\end{abstract}

Keywords - Underwater Buildings, Construction, Materials, Maintenance, Problems

C.D. Modhera, G.J. Joshi, D. Soni, I.N. Patel, A.K. Verma, L.B. Zala, S.D. Dhiman, D.R. Bhatt, J.M. Rathod, B.C. Goradiya, M.S. Holia and D.K. Patel (eds.), ICRISET2017 (Kalpa Publications in Civil Engineering, vol. 1), pp. 37-44 


\section{Introduction}

Underwater buildings are structures which are built under the water and each constructing built has a specific motive related to it in keeping with the type of its construction. The idea of the underwater production become started with through the construction of underwater research stations through Jacques Cousteau's team inside the 1960's. To a layman, he has by no means notion of going to an underwater constructing and through the development of underwater homes it is a new improvement and enhancement of the generation.

Underwater construction is the destiny goal or future foundation so that you can have an splendid impact on the environment, it will additionally lead to some of the troubles to the surroundings which will be confronted because of the application of this technology but if we get fulfilment in reaching it will be a tremendous gain to the environment which is getting crowded day by day due to the growing populace. Approximately 3/4th of the earth's floor is protected with the aid of water and water our bodies. For this reason the development closer to the underwater production technology will be useful to the mankind.

\subsection{Benefits of Constructing Underwater structures}

Underwater construction will have great benefits to the people living in India. There will be a decrease in the populated places present on the surface of land. There will be a progress and enhancement in technology used for its construction. It will promote tourism as all the people from all over the world would come for the astonishing experience of numerous fishes and coral and it will be provide as a source of entertainment for them. And also the corals will be protected from the touching and diving of the people. The people will get fascinated by it and if this idea gets success then it will get easily spread among the people. After asking some people it was found that most of the people accepted the idea of going to the underwater city for the means of entertainment or in order to get a new exotic experience. Hence this project may get success.

\subsection{Social aspects}

Over population is considered as the sector problem that is increasing at a high pace and this result in big quantity of issues. And we understand that the blue colour dominates the earth therefore these motives have let the humans consider the opportunity of the underwater constructions. Now, the point is will people accept the notion of living underwater in future or this project will turn out of no use.

because of the high price of construction those underwater building may also get confined to the sure amount of people who are capable of find the money for it and this will be considered because the signal of wealthy human beings. allows think that if the era gets development there might be the discount, however if entire cities are built underneath the water it'd be difficult for the human beings to accepts the sort of alternate and to live there, due to the fact some people wishes solar and as this underwater cities are some distance faraway from regular world some human beings might think that they would get remoted. Others may additionally actually need to strive the brand new lifestyles and revel in the calmness, peace and fantastic view of nature.

\subsection{Means of Transportation}

After questioning the possibility of underwater constructing, one of the most critical issue that comes in mind would be the approach of transportation. There are basically possibilities, first as most of people would assume a submarine may be the primary mean of transportation but whilst considering the application and price we find it is appropriate. If we communicate about the large scale, the idea of underwater tunnels can be taken into consideration. There are by now present some underwater tunnels 
which might be operative for some future underwater buildings. We can take the example of the underwater hotel "Hydropolis" of Dubai, which is still under construction. It has been explained by the developers of this project that: "It will be inclusive of three elements: the land station, where guests will be welcomed, the connecting tunnel, where the guest will be transported to the prime area of the hotel by the means of trains, and the 220 suites within the submarine leisure complex."

\subsection{Materials used}

There are many materials to be had for the building but our selection should be such that the material fulfils our requirement and to be had with a minimal price. Whilst choosing the materials to be used inside the manufacturing, it is critical to make sure that the burden restriction is not exceeded. The principle fabric used for construction underwater changed into a unique kind of steel and acrylic. The acrylic fabric is used specifically for visibility, on the same time because the steel is used for reinforcements (enables). Excessive energy steel is used as it is in particular reasonably-priced, and has its immoderate yield electricity. It isn't always additionally a terrific conductor of power and warmth. It's far an excessive corrosion resistance. Acrylic fabric is used in preference to glass; it is better than glass due to being much less dense, and it's also has higher effect electricity than the glass. Acrylic gives the herbal duration and colourings of the encompassing materials than glass. It's also proper insulator of strength which is good in searching out the fitness and safety of clients and underwater creatures.

\subsection{Construction of the Building}

Its miles stated that the pays for underwater creation might be more than on land manufacturing, because of the difficulty faced inside the path of the running underwater. Some other hassle would get up; the building is large in size. For solving those issues, they divide the building into elements and constructing every part on land then assemble them under the water.

\subsection{Maintenance}

The maintenance method is a high-priced gadget especially when dealing with an underwater protection. This hassle may be solved, by way of dividing the constructing into components that can be separated from the complete building; those additives can be transferred to land in order that a less highpriced renovation can take area. The apparent a part of the constructing want to be usually clean, so that the customers can see the marine surely in all the time. This situation can be executed through an automated gadget which may be used as self-cleansing system. 

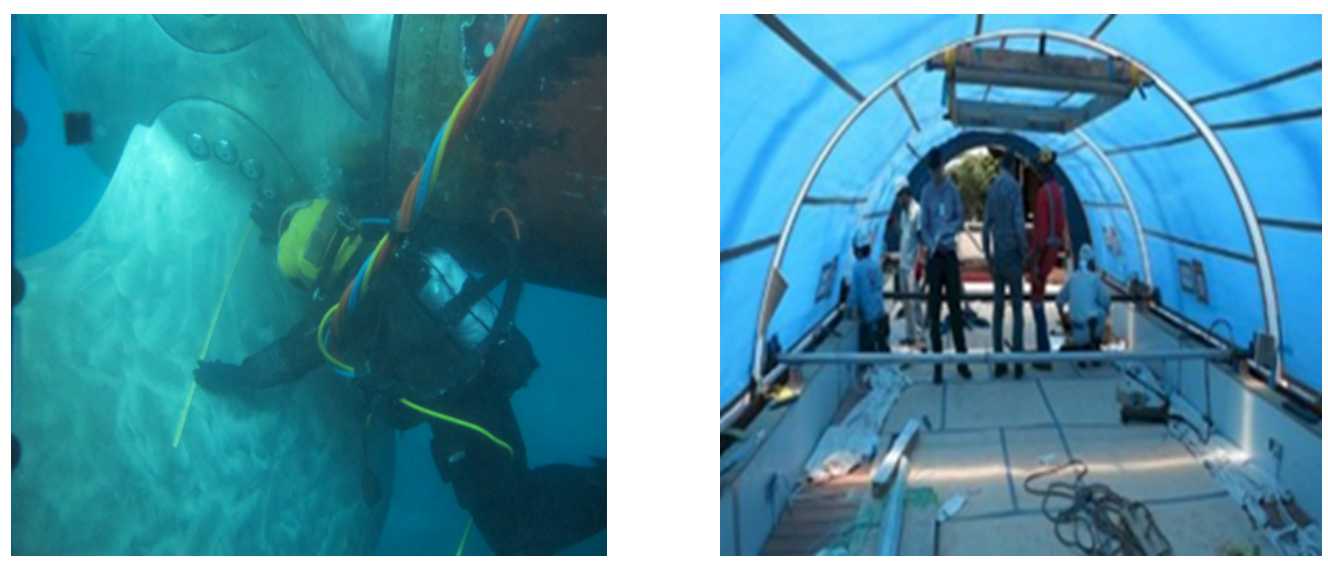

\section{The Problems Confronted by Underwater Building}

\section{[1] Budget}

Building beneath water is a very costly way because of using heavy machinery, devices and professional employees. Building below water also includes some of welfare and it desires to large price range.

[2] Erosion

Erosion is the method of weathering and delivery of solids (sediment, soil, rock and different rock particles) in the natural surroundings or their source and deposits them someplace else. It normally takes place because of transport with the resource of wind, water, or ice so engineers ought to pick out appropriate materials for beneath water building.

\section{[3] Location of fuel}

Any coincidence may also be possible when the driller machines and other machinery are trying to find out oil or to any ship also can damage the outlook and structure of the building it's far out of manage.

\section{[4] The hassle of warmth of the water}

The temperature varies reasonably over the surface of water, it is heated from the ground from the below by the usage of daylight hours, but at depth maximum of the water may be very cold.

[5] The problem of pressure

Stress performs a large characteristic in persuading the guidelines of the constructing additionally people comes to problems one or the other at some stage in the development system or at some point of the protection procedure.

[6] Environmental building elements

No doubt that the primary problem that is to be had in our mind at the equal time as talking approximately the development of underwater systems is the problem of aeration. There need to be a supply of renewable air that helps in respiratory, and removing unwanted gases. Permits discover a solution, for the air flow hassle, that changed into implemented at the same time as the development of the underwater Holland tunnel. Tunnels, in particular, have a exceptional trouble with ventilation, due to gases produced thru trains and cars. This hassle modified into addressed with the aid of Clifford Holland, the tunnel's clothier. His intention was to find ways to easy exhaust fumes and pump in clean air, reaching this with the aid of manner of the usage of aeration towers, and enthusiasts to transport air in and out. In the end, air can be transformed each ninety seconds. 


\section{Case Studies}

\subsection{Dubai Underwater resort}

It's far nevertheless beneath development. The motel is located at 33 feet below the surface of water. The total cost of this project is over $\$ 550$ million. The surface station can be related with the main project below the water with a 515 meter lengthy tunnel via which a spontaneous teaches will be shipping people to the underwater motel. It is 260 hectares place consisted of the bubble shaped suits 220 in numbers which are formed at 20 meters beneath the surface of the water.

The hotel may even have many safety features. It consists of sequence of waterproof entrances which can be used in case of any rapture. It's going to additionally have its personal missile protecting machine in the situation of any extremist assault.
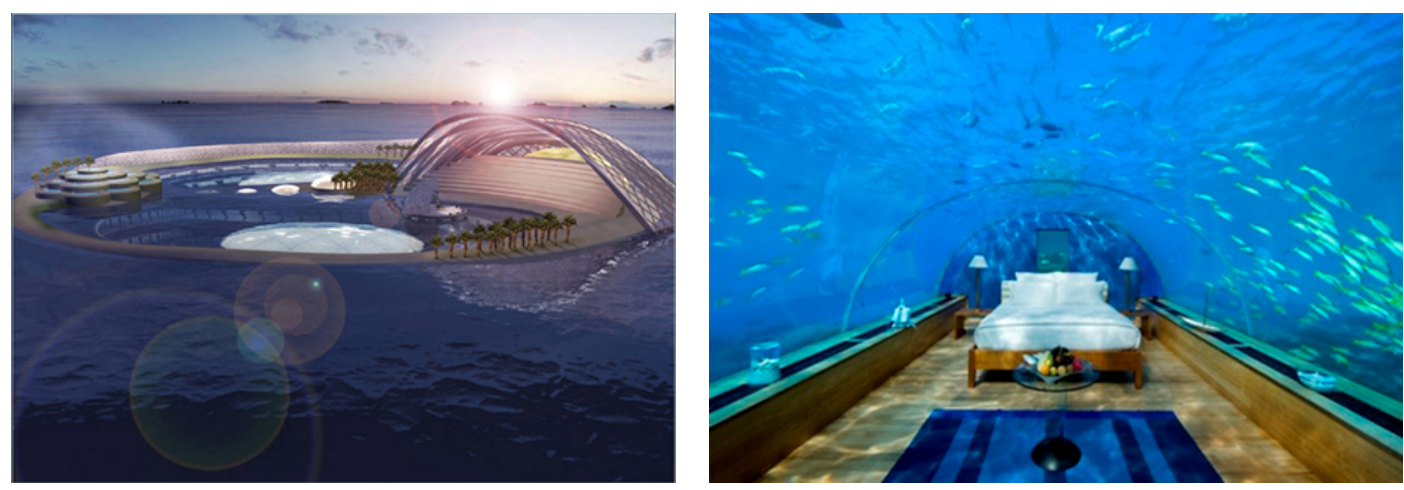

\subsection{UNDERSEA - The Poseidon Luxurious Resort}

The notion was developed by an American engineer Bruce Jones. The Poseidon resort as shown in the figure can be reached with the help of the elevator. It is built up in the area of 11 lakh rectangular foot. The area of every room comprises of 550 rectangular foot. The total cost for the development of this project was 100 million dollar. 

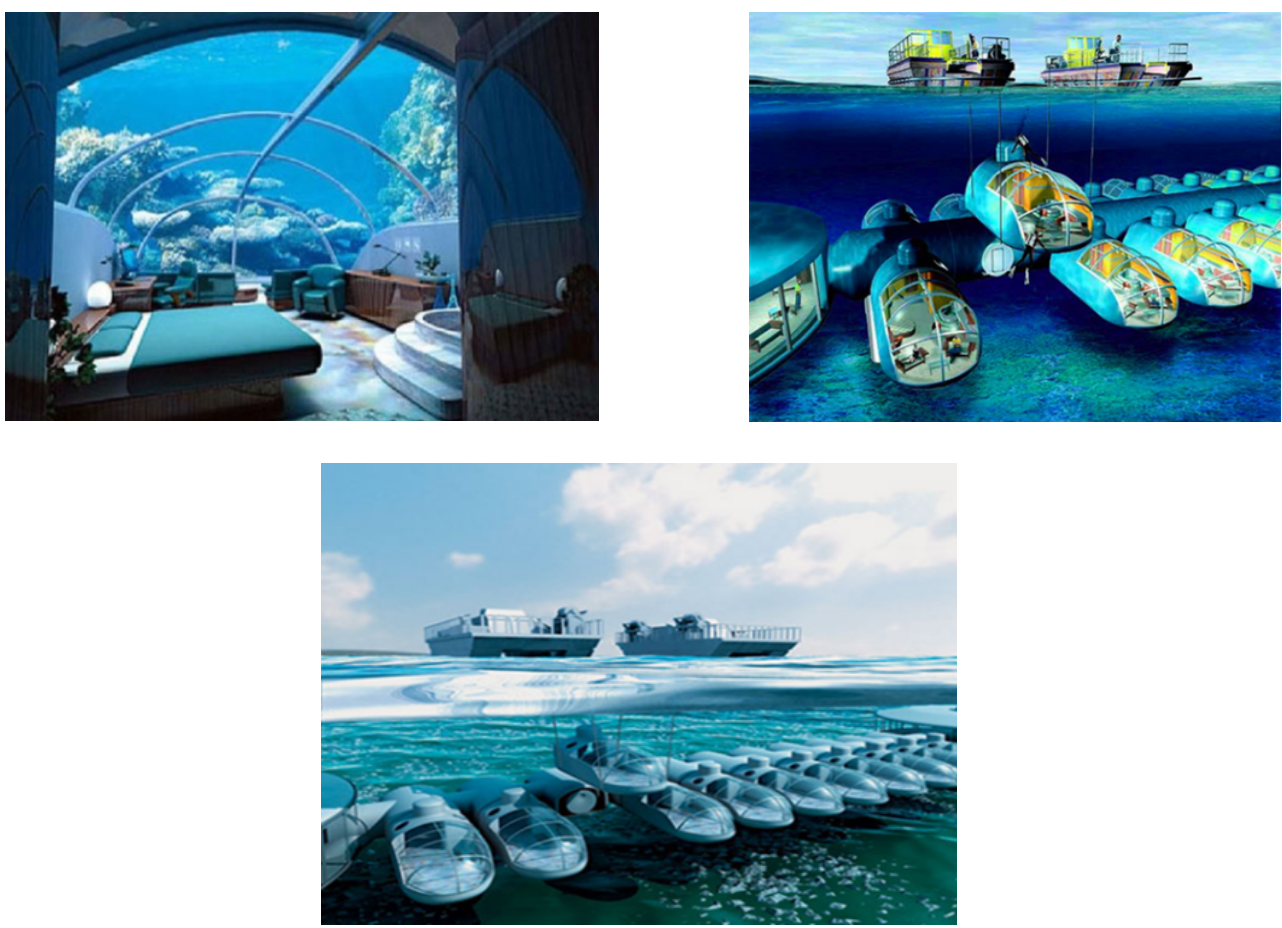

\subsection{The Underwater Restaurant - Itha}

It is the first underwater restaurant built throughout the globe. It is located 16 feet below the surface of water in the Indian Ocean. He outside is covered with clear acrylic.

A person can reach to the eating place of itha restaurant with the help of the wooden walkway as shown in the figure below. The construction and development of this restaurant was difficult on the beach of rangali because of technical problems, restricted assets and exceptional troubles.

The construction was done in Singapore. Its development started in the year 2004, and the work got over in October 2004 together with set up of the acrylic transparent arches, air conditioners and electric powered channels. The duration of its existence is 20 years.
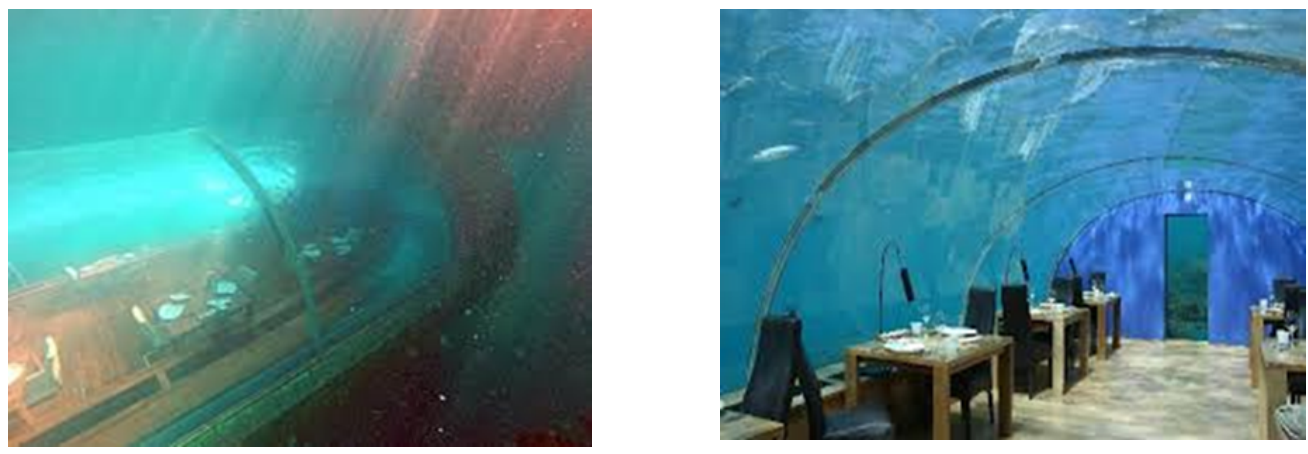


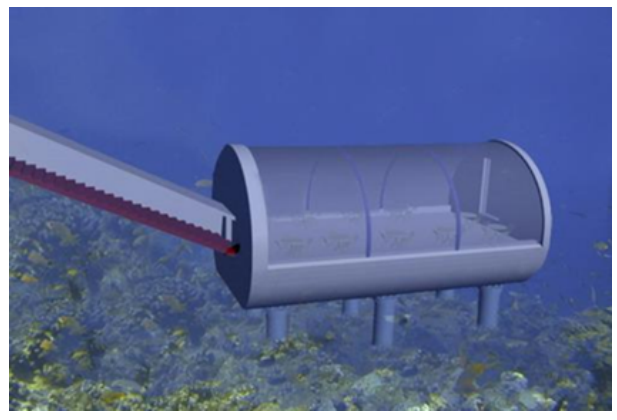

\subsection{Louis C Baleros "Famed Hong Kong inn on Harbour's area"}

This assignment is help to make a dramatic elevation of the shape. The famed resort is the shape of elliptic and 1/2 component is submerged to the ocean water. This shape like a deliver. It counters stability it's self-weight and imposed loads.

It is used to make a brilliant interior for the structure. This lodge comprise Mini Island of parks itself. It facilitates to offer Evans dreamed up the floating structure, which affords guests with a unique way to experience the awesome Barrier Reef. Available best through boat or helicopter, maximum site visitors arrive through excessive velocity catamaran to enjoy an afternoon of scuba diving, snorkelling, and sunbathing.

\subsection{Jordan G. Teicher "Florida's bizarre and delightful Mermaid theme Park"}

This mission is helpful for make glass curtain partitions. Essentially the underwater museum type of systems are make a pitcher curtain walls to seen the outstanding perspectives under the sea.

Which sort of glass fabric is used for below water production? The hassle arise throughout offer the glass walls to withstand the excessive pressure of below water. So the glass is well designed to withstand the forces.

The way to provide the leak evidence joints on glass. The glass walls are provide under the water to make a joint for one to every other. Such joints making through leak evidence substances to avoid the leakage of sea water.

\section{Conclusion}

This record analysed a present day generation of construction of structures beneath the water. Constructing building under the water is the future establishment that has a superb effect on the environment. This document has shown up what underwater buildings are. It has mentioned the impact of underwater constructions on environment and social existence. It has tested the materials which can be utilized in underwater constructing. It additionally has described the problems that are faced during the construction of structures below the water. It has described the air flow structures which are used. It has higher the reader with a few examples of underwater constructions that have been built or under manufacturing, in order to mesmerize him with the appealing view and the magnificence of buildings. 
So this document acclaims the reader to don't forget this technology of building, and convince him to stay down there.

\section{Acknowledgement}

I express sincere and heartfelt thanks to Dr. Indrajit N. Patel, Principal, Birla Vishvakarma Mahavidyalaya Engineering College, Vallabh Vidyanagar, Dr. L. B. Zala, Professor and Head of Department, Civil Engineering Department, Birla Vishvakarma Mahavidyalaya Engineering College, Vallabh Vidyanagar, Prof. J. J. Bhavsar, Associate Professor and PG Coordinator of Construction Engineering and Management, Civil Engineering Department, Birla Vishvakarma Mahavidyalaya Engineering College, Vallabh Vidyanagar and Dr. Jayeshkumar Pitroda, Assistant Professor, Civil Engineering Department, Birla Vishvakarma Mahavidyalaya Engineering College, Vallabh Vidyanagar for guiding me and giving me continuous technical support.

\section{References}

http://vizts.com/hydropolis-dubai-underwater-hotel/

http://www.dailymail.co.uk/travel/travel_news/article-2757717/Five-star-luxury-underwater-

hotel-Poseidon-Underwater-Resort-Fiji-delays-opening-SIX-YEARS.html

https://en.wikipedia.org/wiki/Poseidon_Undersea_Resorts

http://conradhotels3.hilton.com/en/hotels/maldives/conrad-maldives-rangali-island-

MLEHICI/amenities/restaurants-ithaa.html http://www.businessinsider.in/Inside-Floridas-Beautiful-And-Strange-Mermaid-Theme-Park-

PHOTOS/articleshow/27549058.cms

www.poseidonresorts.com 